ORIGINAL ARTICLE

\title{
Causes of apparent life threatening events in infants: a systematic review
}

\author{
M C McGovern, M B H Smith
}

Arch Dis Child 2004;89:1043-1048. doi: 10.1136/adc.2003.031740

See end of article for authors' affiliations

.....................

Correspondence to: $\operatorname{DrMBH}$ Smith, Consultant Paediatrician, Department of Paediatrics, Craigavon Area Hospital, Lurgan Road, Portadown BT63 $5 Q Q$, Co. Armagh, Northern Ireland, UK msmith@cahgt.n-i.nhs.uk

Accepted 19 February 2004
Aims: To determine the most likely diagnoses when infants first present with an apparent life threatening event (ALTE).

Methods: Medline (1966-2002), Embase (1980-2002), and Cinahl (1982-2002) were searched. Primary authors and content experts were contacted to identify further studies. Bibliographies from studies, reviews, and textbooks were searched. Foreign language studies were translated. Articles were included if the ALTE was clearly defined and if the evaluation recorded was from the initial contact. Case reports and studies focusing on single conditions or non-clinical data were excluded.

Results: From an initial 2912 papers, eight studies involving 643 infants (aged 0-13 months) were included. All studies were non-randomised and methodological quality varied. All diagnoses were made after evaluation in hospital but investigation protocols varied widely. There were 728 diagnoses assigned overall. Some infants had multiple diagnoses. The most common diagnoses were gastro-oesophageal reflux $(n=227)$, seizure $(n=83)$, lower respiratory tract infection $(n=58)$, and "unknown" $(n=169)$. Five deaths were noted in total.

Conclusions: There is a wide range of diagnoses reported after evaluation of an ALTE. Differing management protocols contributed to variations in the frequency of the diagnoses. The development and validation of an evidence based management plan may contribute to the care of this common condition.

\section{A} n apparent life threatening event (ALTE) was defined in 1986 by the National Institutes of Health Consensus Development Conference on Infantile Apnoea and Home Monitoring as "an episode that is frightening to the observer and that is characterised by some combination of apnoea (central or occasionally obstructive), colour change (usually cyanotic or pallid but occasionally erythematous or plethoric), marked change in muscle tone (usually marked limpness), choking or gagging" ${ }^{1}$ This new definition replaced existing terms such as "near-miss sudden infant death syndrome" or "aborted cot-death" which are potentially misleading as they imply a close association with sudden infant death syndrome (SIDS). Although the relation between ALTEs and SIDS has still not been firmly established, it is likely there is only a small overlap between the two populations.

It has been our experience that infants who present to the clinician because of an ALTE, particularly those who subsequently appear well, are a challenging group to manage as it can be difficult to decide on an appropriate investigation plan. The first step in the development of an evidence based management algorithm would be to review the diagnoses reported after evaluation of ALTEs but, to our knowledge, there are no systematic reviews that have looked critically at this in unselected infants.

The aim of this systematic review is therefore to determine the diagnoses reported after the first evaluation of an ALTE in infants.

\section{METHODS}

\section{Data sources and search strategy}

The following question was structured to address the clinical query: "In infants, presenting with an ALTE, what is the frequency of underlying disorders?". We searched for studies that considered a range of diagnoses in infants presenting directly to an emergency department or general paediatric ward after an ALTE. A search was performed of the databases
Cinahl (1982-2002), Embase (1980-2002), Medline (19662002) in September 2000 and November 2002. No restrictions were made on language or on the type of article to be included. In addition, reference lists were searched and contact was made with experts in the field.

\section{Study selection (inclusion and exclusion criteria)}

There were three stages in the selection process. Firstly, the titles, abstracts, and descriptor terms of all the citations were inspected for relevance by one author (MCMcG). Articles were selected for inclusion at the first stage if they appeared to address the clinical question. Where there was uncertainty the full article was included. Secondly, articles were assessed for inclusion independently by both authors after evaluation of the full text and according to the following predetermined criteria. Articles were included if a range of diagnoses was reported in a group of infants with ALTE and there was a clear definition of ALTE in the text. Articles were excluded if the study focused on physiological data or polygraphic studies. Thirdly, articles were selected for the final summary if the investigations reported were the first undertaken and if all presenting infants were studied. Any disagreements were resolved by consensus. If data in papers from the same centre were noted to overlap, the most comprehensive study was selected. ${ }^{23}$

\section{Data extraction and synthesis}

One author (MCMcG) extracted data. The primary outcome of interest was the final diagnosis assigned but details of incidence, investigation plans, follow up, recurrence, and deaths were also noted. Individual studies were reported separately and a narrative synthesis of data was performed.

\section{RESULTS}

\section{Study selection}

We identified 2912 citations: 2882 electronically, 29 from reference lists, and one after personal contact with experts. ${ }^{3}$ 
Table 1 Characteristics of included studies

\begin{tabular}{|c|c|c|c|c|c|c|}
\hline & First author, country & Centre, dates of episodes & No. & $\begin{array}{l}\text { Definition of target population } \\
\text { Exclusions }\end{array}$ & $\begin{array}{l}\text { Inv. } \\
\text { proto. }\end{array}$ & Participants \\
\hline A & $\begin{array}{l}\text { Davies (2002), } \\
\text { England }^{5}\end{array}$ & $\begin{array}{l}\text { ED, children's hospital, } \\
\text { 1996-97 (prospective) }\end{array}$ & 65 & $\begin{array}{l}1986 \text { consensus definition } \\
\text { Exclusions: infants }>6 \text { mth with febrile convulsion. }\end{array}$ & Yes & $\begin{array}{l}\text { age } 0-12 \text { mth, median } \\
7 \text { weeks, } 15 \% \text { SIDS in } \\
\text { relative, } 15 \% \\
<34 \text { weeks preterm }\end{array}$ \\
\hline$B$ & $\begin{array}{l}\text { Gray (1999), } \\
\text { England }^{6}\end{array}$ & $\begin{array}{l}\text { ED, children's hospital, } \\
1993 \text { (retrospective) }\end{array}$ & 130 & $\begin{array}{l}\text { Episode with one or more of the following: apnoea, } \\
\text { colour change, choking, abnormal limb movements, } \\
\text { causing observer to seek medical help. } 130 \text { infants } \\
\text { had } 163 \text { ALTE episodes requiring admission. } \\
\text { Exclusions: infants }>6 \text { mth with febrile convulsion. }\end{array}$ & No & $\begin{array}{l}\text { age } 0-12 \text { mth, median } \\
8 \text { weeks, } 3.1 \% \text { SIDS in } \\
\text { close family }\end{array}$ \\
\hline C & $\begin{array}{l}\text { Kurz (1997), } \\
\text { Austria }^{2}\end{array}$ & $\begin{array}{l}\text { Paediatric dept, university } \\
\text { hospital (prospective) }\end{array}$ & 60 & $\begin{array}{l}\text { Episode of sudden, unexpected pallor or cyanosis with } \\
\text { lifelessness, experienced by parents as mortal threat. } \\
\text { No exclusions. }\end{array}$ & Yes & $\begin{array}{l}\text { age } 1-45 \text { weeks, } \\
\text { median } 16 \text { weeks, } 22 \% \\
\text { preterm }\end{array}$ \\
\hline$D$ & $\begin{array}{l}\text { Laisne (1989), } \\
\text { France }\end{array}$ & $\begin{array}{l}\text { Paediatric dept, general } \\
\text { hospital, 1985-87 } \\
\text { (retrospective) }\end{array}$ & 100 & $\begin{array}{l}\text { Episode of sudden, unexplained apnoea with cyanosis } \\
\text { and/or pallor and hypotonia leading to loss of } \\
\text { consciousness and often prompting carers to stimulate } \\
\text { the infant. } \\
\text { No exclusions. }\end{array}$ & Yes & $\begin{array}{l}\text { mean } 13 \text { weeks, } 90 \% \\
<6 \mathrm{mth}\end{array}$ \\
\hline$E$ & $\begin{array}{l}\text { Sheikh (2000), } \\
\text { USA }^{10}\end{array}$ & $\begin{array}{l}\text { ED, children's hospital, } \\
1993-97 \text { (retrospective) }\end{array}$ & 74 & $\begin{array}{l}\text { Episode of prolonged apnoea, hypotonia and } \\
\text { pallor or cyanosis in first year of life. } \\
\text { No exclusions. }\end{array}$ & No & $\begin{array}{l}\text { age } 0-12 \mathrm{mth} \text {, mean } \\
7 \text { weeks, } 0 \% \text { preterm }\end{array}$ \\
\hline $\mathrm{F}$ & Tal (1999), Israel ${ }^{8}$ & $\begin{array}{l}\text { Paediatric ward, general } \\
\text { hospital, 1993-95 } \\
\text { (retrospective) }\end{array}$ & 65 & $\begin{array}{l}1986 \text { consensus definition. } \\
\text { No exclusions. }\end{array}$ & Yes & age $1-6 \mathrm{mth}$ \\
\hline G & $\begin{array}{l}\text { Tsukada (1993), } \\
\text { Japan"1 }\end{array}$ & $\begin{array}{l}\text { Paediatric ward, general } \\
\text { hospital, 1986-91 } \\
\text { (retrospective) }\end{array}$ & 19 & $\begin{array}{l}1986 \text { consensus definition. } \\
\text { No exclusions. }\end{array}$ & Yes & $\begin{array}{l}\text { age } 23 \text { days }-13 \text { mth, } \\
\text { mean } 19 \text { weeks }\end{array}$ \\
\hline $\mathrm{H}$ & $\begin{array}{l}\text { V-Wauters (1991), } \\
\text { Belgium? }\end{array}$ & $\begin{array}{l}\text { ED, children's hospital, } \\
1984-86 \text { (retrospective) }\end{array}$ & 130 & $\begin{array}{l}\text { Episode of prolonged apnoea, hypotonia, and cyanosis } \\
\text { or pallor. } \\
\text { No exclusions. }\end{array}$ & Yes & age $2-36$ weeks \\
\hline \multicolumn{7}{|c|}{$\begin{array}{l}\text { ED, emergency department. } \\
\text { Prospective, prospective identification of patients. } \\
\text { Retrospective, retrospective case note review. } \\
\text { Inv. proto., investigation protocol. }\end{array}$} \\
\hline
\end{tabular}

The selection process identified eight studies, involving 643 infants, in which a range of differential diagnoses was described in a group of infants undergoing a first evaluation of ALTE. Agreement between reviewers was good (kappa $\left.0.71^{4}\right)$.

\section{Study quality}

Table 1 presents study characteristics. All studies were nonrandomised, descriptive studies.

\section{Investigation plans}

All diagnoses were made after evaluation in hospital. The range of investigations in each study varied and in six an investigation protocol was described (table 2).

\section{Incidence of ALTE}

The incidence of ALTE was described in four studies as $0.6-0.8 \%$ of all emergency visits of those under 1 year, ${ }^{5}{ }^{6} 2.27 \%$ of hospitalised children, ${ }^{7}$ and $0.6 / 1000$ live born infants. ${ }^{2}$

\section{Final diagnoses}

Table 3 presents final diagnoses. In seven studies each infant was assigned a definitive diagnosis or in some cases multiple diagnoses after an ALTE. In one study some infants presented more than once to the emergency department and the diagnosis made after each episode is recorded. ${ }^{6}$ There were 728 diagnoses assigned in total with 50 different diagnoses recorded. The commonest diagnoses made were gastrooesophageal reflux disease (GORD), lower respiratory tract infection (LRTI), and seizure.

Table 2 Baseline investigations for all infants in six studies with protocols

\begin{tabular}{|c|c|c|c|c|c|c|c|c|c|c|c|c|c|}
\hline & A & $\mathrm{C}$ & D & $\mathbf{F}$ & G & $\mathbf{H}$ & & A & C & D & $\mathbf{F}$ & G & H \\
\hline Basic blood tests & & & & & & & Metabolic work up & & & & & & \\
\hline $\mathrm{FBC}, \mathrm{U}+\mathrm{E}$, glucose & + & + & + & + & + & + & Lactate, ammonia & + & - & - & - & - & - \\
\hline Calcium, magnesium & - & + & + & + & + & + & Serum amino acids & + & - & - & - & - & + \\
\hline Liver function tests & - & + & - & + & - & - & Urine organic acids & + & - & - & - & - & + \\
\hline Blood gas or bicarbonate & + & + & - & + & + & + & Urine reducing substances & + & - & - & - & - & - \\
\hline Thyroid hormones & - & - & - & - & - & + & Cardiology & & & & & & \\
\hline CPK & - & + & - & - & - & - & ECG & + & + & + & + & + & + \\
\hline Infection screen & & & & & & & 24 hour tape & - & - & * & - & - & - \\
\hline Blood culture & - & - & - & - & - & - & Echocardiography & - & - & - & - & + & - \\
\hline Urinalysis or culture & + & + & + & - & - & - & Other & & & & & & \\
\hline Chest $x$ ray & + & + & + & - & + & + & Toxicology screen & + & - & - & - & - & + \\
\hline If secretions present: & & & & & & & Electroencephalogram (EEG) & - & - & - & + & + & + \\
\hline Pertussis swab & + & - & - & - & - & - & Polysomnograph & - & + & * & - & - & + \\
\hline Virology tests & + & - & - & - & - & - & ENT consultation & - & - & - & - & - & + \\
\hline Bacteriological tests & - & - & - & - & - & - & Milk scan or barium swallow or $\mathrm{pH}$ studies & + & - & * & - & + & - \\
\hline
\end{tabular}

*Performed in second year of study.

CPK, creatinine phosphokinase.

Note: all studies performed additional investigations in selected infants as clinically indicated. 


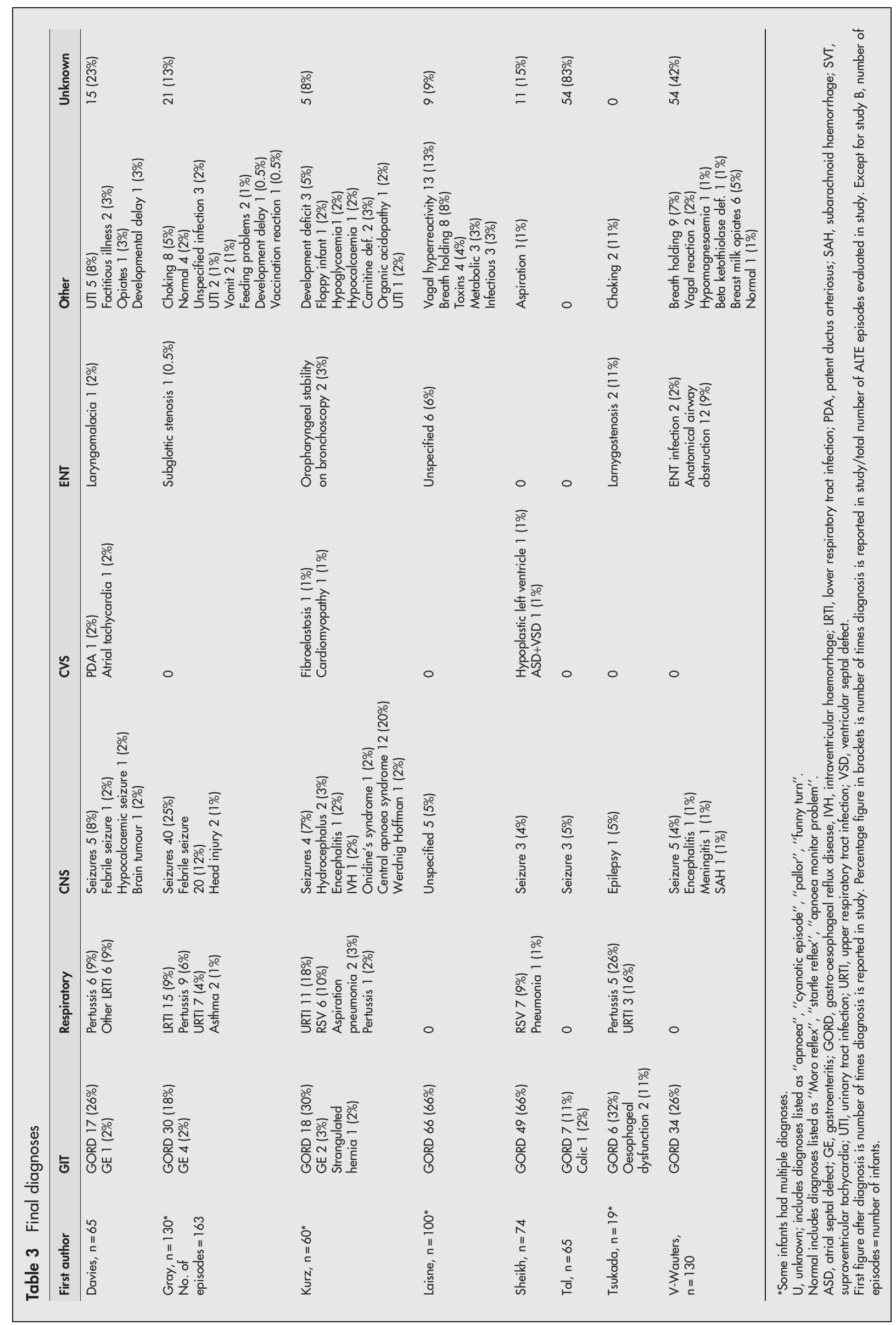


Gastro-oesophageal reflux disease

This was reported in every study $(n=227,31 \%$ of total diagnoses). The diagnosis was assigned after $\mathrm{pH}$ studies only, ${ }^{89} \mathrm{pH}$ studies or barium studies, ${ }^{10}$ milk scans in combination with clinical findings, ${ }^{5} \mathrm{pH}$ studies or barium and manometric studies, ${ }^{11} \mathrm{pH}$ studies or manometry. ${ }^{2}$ In two studies some infants were assigned the diagnosis on clinical grounds. ${ }^{67}$

\section{Seizure}

This was reported in seven studies $(\mathrm{n}=83,11 \%$ of total diagnoses), with the eighth describing "neurological causes" as a group. Two studies reported abnormal electroencephalogram (EEG) findings in the infants with seizures, ${ }^{21}$ but the others did not describe assignment criteria.

Lower respiratory tract infection (LRTI)

The diagnoses "pertussis" and "respiratory syncytial virus infection" were included under LRTI which was reported in five studies ( $\mathrm{n}=58,8 \%$ of all diagnoses). Pertussis was diagnosed by postnasal swab or typical clinical findings with a lymphocytosis, ${ }^{5}$ bacteriological investigations, ${ }^{2}$ and by rising pertussis antibody titre. ${ }^{11}$ One study did not record assignment criteria. ${ }^{6}$

\section{Other diagnoses}

Ear, nose, and throat (ENT) problems were reported in six studies $(\mathrm{n}=26,3.6 \%$ of all diagnoses). Cardiac problems were noted in three studies ( $\mathrm{n}=6,0.8 \%$ of all diagnoses). Urinary tract infections were reported in three studies $(n=8$, $1.1 \%$ of all diagnoses) and may have been classified under "infection" in a fourth. Metabolic disease was diagnosed in four studies $(\mathrm{n}=11,1.5 \%$ of all diagnoses), ingestion of drugs or toxins was reported in three $(n=11,1.5 \%$ of all diagnoses), breath holding was noted in two $(n=17,2.3 \%$ of all diagnoses), and factitious illness was diagnosed in one $(\mathrm{n}=2,0.3 \%$ of all diagnoses $)$. Only five ALTE episodes were felt to be completely benign ( $0.7 \%$ of all diagnoses).

\section{Unknown diagnoses \\ "Diagnosis unknown" was reported in seven studies $(\mathrm{n}=169,23 \%$ of all diagnoses $)$.}

\section{Long term follow up}

Davies and Gupta reviewed the case notes in $98 \%$ of infants after six months and Gray et al tracked all infants on computer for 18 months. ${ }^{5}{ }^{6}$ Tal et al followed up all infants for 12 months and Veereman-Wauters et al reviewed 22\% after six months. ${ }^{8}$ Kurz et al and Laisne et al commented on recurrences and deaths but did not give follow up details. ${ }^{2} 7$ Recurrences of ALTEs varied between 0 and $24 \% .^{2}{ }^{5} 8$

Five deaths were reported ( $0.8 \%$ of all infants). In one study, ${ }^{9}$ two infants with severe GORD died during sleep, and three infants in another ${ }^{2}$ had rare, congenital metabolic disorders.

\section{DISCUSSION}

An ALTE is a common problem in infancy, often presenting a management dilemma, particularly when the infant subsequently appears well. The history and examination may provide clues to the cause, but when they do not, it is difficult to decide how intensively to seek a diagnosis. This systematic review has identified the common pathological conditions associated with an ALTE, highlighted rarer diagnoses to be considered, and confirmed that, in a significant number of infants, no underlying cause is identified at the initial evaluation.

The definition of an ALTE is subjective, and therefore its incidence is difficult to determine accurately. A prospective study over two years covering almost $40 \%$ of all births in Sweden reported an incidence of 0.46/1000 live births, but apnoeic episodes for which medical causes were identified were excluded. ${ }^{12}$ A retrospective study of severe ALTEs (requiring basic resuscitation) reported an incidence of 0.9/ 1000 live births. ${ }^{13}$ From these eight studies, it is clear that ALTEs are a common problem for paediatricians worldwide but, because different measures were used to report frequency, no consensus can be drawn about incidence.

There was a wide range of diagnoses reported among all studies. GORD was the most common diagnosis and the only one to appear in every study. However, there is little consistency in its frequency of diagnosis among studies. This may relate to different investigations for GORD and whether these were performed in all or selected infants. Other studies have reported incidences of GORD after ALTEs of $42 \%, 53 \%$, and $54 \%{ }^{14-16}$

Seizure was diagnosed at a more constant frequency than GORD in most studies, possibly because all clinicians use the same diagnostic tools. It is well documented that apnoea may be a manifestation of seizures in infancy, and this review confirms that investigation for seizures is useful in an ALTE. ${ }^{17-20}$

LRTI was another common diagnosis but again the frequency of diagnosis varied widely. This may be due to epidemic bronchiolitis or pertussis or because LRTIs were classified in one study as "miscellaneous infection". ${ }^{7}$ Up to $20 \%$ of infants under six months hospitalised with respiratory syncytial virus (RSV) infection have been reported to have apnoea, the association being strongest during the first month of life and in infants born prematurely. ${ }^{21}$

Inborn errors of metabolism were a small but significant cause of ALTEs in the review. Other authors have diagnosed metabolic disorders in $7.7 \%$ of infants after ALTEs, ${ }^{22}$ and one study based in a metabolic unit found evidence for a possible fat oxidation disorder in $17 \%$ of infants. ${ }^{23}$

Among the cardiac causes reported, there was just one arrhythmia. There were no reports of a prolonged QTC interval but only two studies measured this. ${ }^{5}$ It has been suggested recently that prolongation of the QTc interval in the first week of life is strongly associated with SIDS, but any association with ALTEs was not explored. ${ }^{24}$

Although factitious illness or Munchausen by proxy (MBP) was reported in just two children overall, it is vital that child abuse is always considered as part of the differential diagnosis of an ALTE. This diagnosis is generally made after recurrent ALTEs, sometimes at tertiary evaluation. MBP has been reported as a cause of apnoea in $0.27 \%$ of infants on home monitoring programmes, ${ }^{25}$ and deliberate suffocation and deliberate poisoning have both been reported as causes of ALTEs. ${ }^{26-28}$

"Unknown diagnoses" were reported in seven studies, but the frequency varied widely $(9-83 \%)$. This may reflect different investigation protocols or assignment criteria. For example, a subjective diagnosis like "breath holding" could be considered by another clinician as "unknown diagnosis". The term "apnoea of infancy" (AOI) may be used for infants greater than 37 weeks gestational age at the onset of apnoea for which no cause can be identified. ${ }^{1}$ However, this diagnosis should not be assigned too readily. Infants with an ALTE for which no cause is initially identified may be assigned diagnoses after specialised investigations.

All of the five deaths reported in this review occurred in infants with an underlying medical problem.

However, a comprehensive follow up was reported in three studies only and so the accuracy of the data on recurrence and deaths is uncertain. Any relation between sudden infant death syndrome and ALTEs is still unclear. Some studies have shown a slight increase in SIDS after an ALTE, while others have not. ${ }^{29-31}$ 


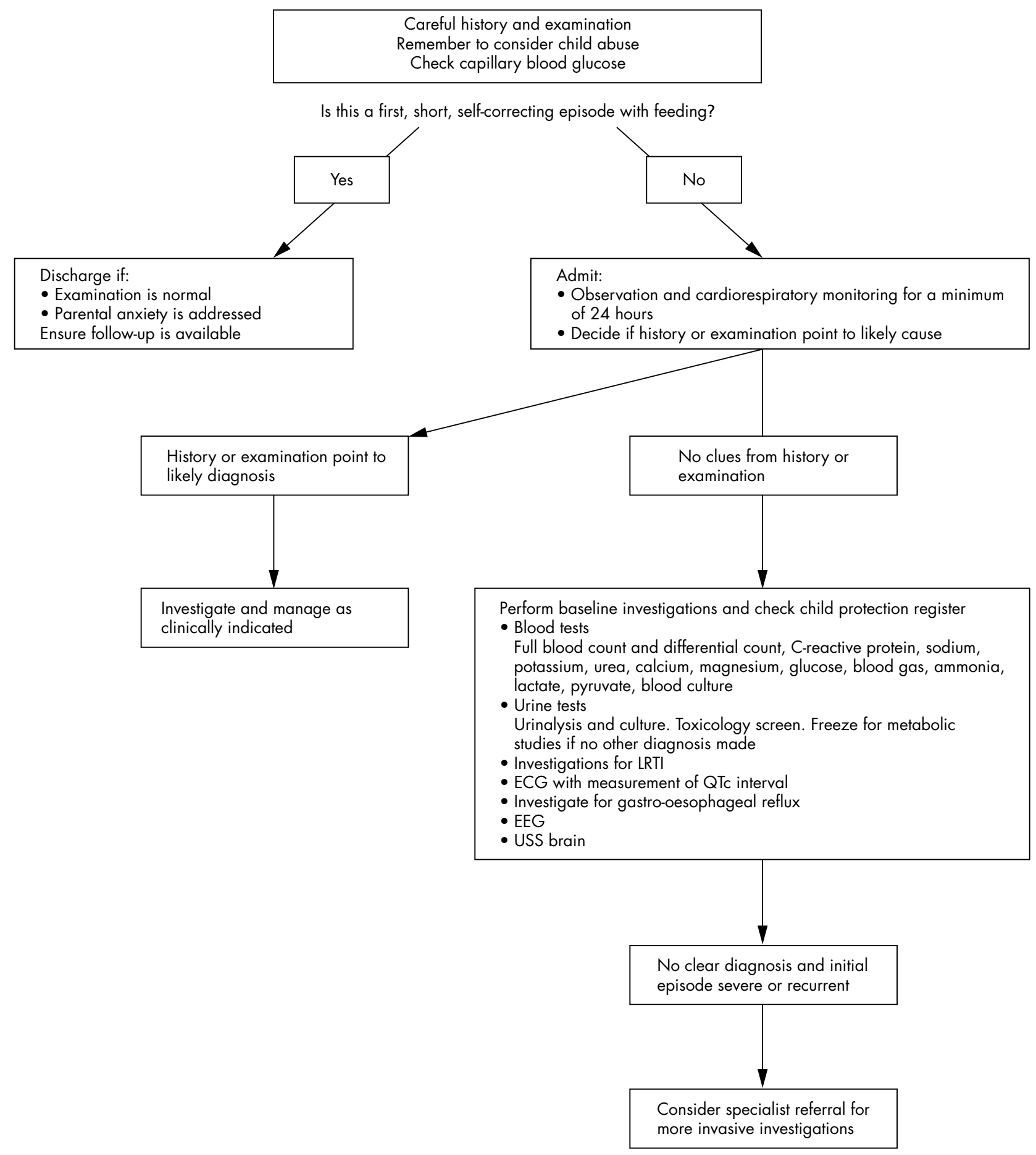

Figure 1 Suggested initial investigation plan for an ALTE in a previously healthy infant.

There were methodological difficulties with the review. Firstly, systematic reviews of diagnoses are often confounded by a lack of well designed studies, and we anticipated that that we would be working with non-randomised studies. Any case-controlled studies in the literature on the diagnoses after ALTEs focus on one cause only and their external validity is limited. Secondly, the quality of the eight studies varied and, in two, ${ }^{8}{ }^{9}$ the primary aim was not to identify the causes of ALTE. We attempted to apply a validity score using the desirable methodological characteristics for studies looking at disease probability, but were unsuccessful. ${ }^{32}$ Thirdly, there were difficulties with data extraction. Some infants had more than one diagnosis and some diagnoses like developmental delay were not specific. Finally, the issue of causation must be addressed because the detection of a disorder after an ALTE does not necessarily mean that the two are associated. For example, there is conflicting evidence as to whether or not the relation between GORD and ALTEs is causal. ${ }^{33}$ Even when an underlying disorder such as RSV infection (which seems to have a clear temporal relation with an ALTE) is detected, the question as to why some infants react to RSV infection with apnoea while others do not is still unresolved. It is likely that several factors interact to produce an ALTE. 


\section{Future directions}

Having determined the diagnoses made at first evaluation of ALTEs, the next step is to address the most appropriate initial investigation plan. Other authors have made suggestions. ${ }^{54-39}$ All emphasise the importance of a thorough history, careful physical examination, and then an initial screen of investigations in all infants followed by additional investigations in some.

Using the diagnoses in table 3, we suggest the investigation plan shown in fig 1 . The use of this approach will depend on the local availability of the investigations. We estimate that in at least $50 \%$ of ALTEs a careful history and examination will point to the diagnosis, and emphasise that the thorough (and expensive) list of investigations in the algorithm are not suggested for all infants. Also, should one of the initial investigations lead to a clear diagnosis, we suggest it is not necessary to proceed with the others.

The subsequent management of an infant with an ALTE depends on the severity of the initial episode, any diagnoses made, and whether episodes are recurrent. Specific recommendations lie outside the scope of this review, but we suggest that all parents should be offered training in cardiopulmonary resuscitation and SIDS prevention advice. Home apnoea monitoring may be an appropriate intervention for some infants.

\section{Conclusions}

An ALTE is similar to other non-specific presenting complaints in infancy such as fever. Many pathological conditions can trigger an ALTE in infancy. A careful history, examination, and appropriate hospital investigations will enable the clinician to identify many of these disorders, but in a significant number no underlying cause will be identified at first presentation. Gastro-oesophageal reflux disease, lower respiratory tract infection, and seizures are the most common diagnoses, but an ALTE may be a presentation of rarer disorders. Child abuse should always be considered in the differential diagnosis. We suggest that it would be useful to develop and validate an evidence based algorithm of practical investigation of infants presenting with ALTEs.

\section{ACKNOWLEDGEMENTS}

We acknowledge the original work of the authors whose studies were selected for critical review and we thank the experts in the field who kindly supplied us with information when requested. We are grateful for help from all of the following: $\mathrm{K}$ Blackhall and D Kennedy performed the literature searches; $\mathrm{H}$ Neale retrieved papers; $\mathrm{A}$ McGovern, B Thompson, D Quinn, and A Volprecht translated foreign language papers; A Talbot and Professor E Trimble commented on the paper.

\section{Authors' affiliations}

M C McGovern, M B H Smith, Department of Paediatrics, Craigavon Area Hospital, Lurgan Road, Portadown BT63 5QQ, Co. Armagh, Northern Ireland, UK

\section{REFERENCES}

1 National Institutes of Health. Consensus Development Conference on Infantile Apnea and Home Monitoring, Sept 29 to Oct 1, 1986. Consensus statement. Pediatrics 1987;79:292-9.

2 Kurz R, Kerbl R, Reiterer F, et al. The role of triggers in apparent lifethreatening events (ALTE). Journal of Sudden Infant Death Syndrome and Infant Mortality 1997;2:3-12.

3 Kurz R, Kenner T, Reiterer F, et al. Factors involved in the pathogenesis of unexpected near miss events of infants (ALTE). Acta Paediatr Hungarica 1990;30:435-47.

4 Cohen J. A coefficient of agreement for nominal scales. Educational and Psychological Measurement 1960;20:37-46.
5 Davies F, Gupta R. Apparent life threatening events in infants presenting to an emergency department. Emerg Med J, 2002;19;11-16..

6 Gray C, Davies F, Molyneux E. Apparent life threatening events presenting to a paediatric emergency department. Pediatr Emerg Care 1999:15:195-99.

7 Laisne $C$, Rimet $Y$, Poujol A, et al. A propos de cent malaises du nourrisson. Ann Pédiatr (Paris) 1989;36:451-4.

$8 \mathrm{Tal} \mathrm{Y}$, Tirosh E, Even L, Jaffe M. A comparison of the yield of a $24 \mathrm{~h}$ versus $72 \mathrm{~h}$ hospital evaluation in infants with apparent life threatening events. Eur J Paediatr 1999;158(11):954.

9 Veereman-Wauters G, Bochner A, Van Caillie-Bertrand M. Gastroesophageal reflux in infants with a history of near-miss sudden infant death. J Pediatr Gastroenterol Nutr 1991;12:319-23.

10 Sheikh S, Stephen T, Frazer A, et al. Apparent life threatening events in infants. Clinical Pulmonary Medicine 2000;7(2):81-4.

11 Tsukada K, Kosuge N, Hosokawa M, et al. Etiology of 19 infants with apparent life threatening events: relationship between apnea and oesophageal dysfunction. Acta Paediatrica Japonica 1993;35:306-10.

12 Wennergren G, Milerad J, Lagercrantz H, et al. The epidemiology of sudden infant death syndrome and attacks of lifelessness in Sweden. Acta Paediatr Scand 1987;76:898-06

13 Davis N, Bossung-Sweeney L, Peterson DR. Epidemiological comparisons of sudden infant death syndrome with infant apnoea. Aust Paediatr J 1986;(suppl):29-32.

14 Sacré L, Vandenplas Y. Gastroesophageal reflux associated with respiratory abnormalities during sleep. J Pediatr Gastroenterol Nutr 1989;9:28-33.

15 Tirosh E, Jaffe M. Apnea of infancy, seizures and gastroesophageal reflux: an important but infrequent association. J Child Neurol 1996;11:98-100.

16 Haney PJ. Infant apnea: findings on the barium esophagram. Radiology 1983; 148:425-7

17 Davis JM, Metrakos K, Aranda JV. Apnoea and seizures. Arch Dis Child 1986;61:791-93.

18 Navelet Y, Wood C, Robieux I, et al. Seizures presenting as apnoea. Arch Dis Child 1989;64:357-9.

19 Ramelli GP, Donati F, Bianchetti M, et al. Apnoeic seizures as an isolated manifestation of epileptic seizures in infants. Eur J Paediatr Neurol 1998;2:187-91.

20 Watanabe K, Hara K, Miyazaki S, et al. Apneic seizures in the newborn Am J Dis Child 1982;136:980-4.

21 Bruhn F, Mokrohisky ST, Mclntosh K. Apnoea associated with respiratory syncytial virus infection in young infants. J Pediatr 1977;90:382-6.

22 Arens R, Gozal D, Williams JC, et al. Recurrent apparent life-threatening events during infancy: a manifestation of inborn errors of metabolism. J Pediatr 1993;123:415-18.

23 Harpey JP, Charpentier C, Paturneau-Jouas M. Sudden infant death syndrome and inherited disorders of fatty acid beta oxidation. Biol Neonate 1990;58(suppl):70-80.

24 Schwartz PJ, Stramba-Badiale M, Segantini A, et al. Prolongation of the QT interval and the sudden infant death syndrome. N Engl J Med 1998;338: 1709-14

25 Light MJ, Sheridan MS. Munchausen syndrome by proxy and apnea (MBPA). Clin Pediatr 1990;29:162-8.

26 Southall DP, Plunkett MCB, Banks MW, et al. Covert video recordings of lifethreatening child abuse: lessons for child protection. Pediatrics 1997; 100:735-60.

27 Samuels MP, Poets CF, Noyes JP, et al. Diagnosis and management after lifethreatening events in infants and young children who received cardiopulmonary resuscitation. BMJ 1993;306:489-92.

28 Hickson GB, Altemeier WA, Martin ED, et al. Parental administration of chemical agents: a cause of apparent life-threatening events. Pediatrics 1989;83:772-6.

29 Oren J, Kelly D, Shannon DC. Identification of a high risk group for sudden infant death syndrome among infants who were resuscitated for sleep apnea. Pediatrics 1986:77:495-9.

30 Dunne K, Matthews T. Near-miss sudden infant death syndrome: clinical findings and management. Pediatrics 1987;79:889-93.

31 Southall DP. Home monitoring and its role in the sudden infant death syndrome. Pediatrics 1983;72:133-8.

32 Richardson WS, Wilson MC, Guyatt GH, et al. How to use an article about disease probability for differential diagnosis. JAMA 1999;281:1214-19.

33 Amin RS. Gastroesophageal reflux and infant apnea. J Pediatr 2000; 137:298-300.

34 Wennergren G, Milerad J, Westphall I, et al. Consensus statement on clinical management. Acta Paediatr 1993;389(suppl):114-16.

35 Brooks JG. Apparent life-threatening events and apnea of infancy. Clin Perinatol 1992; 19:809-38.

36 Spitzer AR, Fox WW. Infant apnea; an approach to management. Clin Pediatr (Phila) 1984;23:374-80.

37 Guilleminault C, Korobkin R. Sudden infant death: near miss events and sleep research. Some recommendations to improve comparability of results among investigators. Sleep 1979;1:423-33.

38 McBride J. Infantile apnea. Pediatr Rev 1984;5:275-84.

39 Gibb SM, Waite AJ. The management of apparent life threatening events. Curr Paediatr 1998;8:152-6. 